evacuated. Through the enlarged opening an ovoid uric acid calculus measuring 1 in. by $\frac{1}{2}$ in. was extracted; it was lying loose in the abscess cavity. No other stone could be felt either in the kidney or the nreter and it was considered inadvisable to make any prolonged search, although the opinion was held that the cause of the condition had not been found. This opinion was confirmed by the later progress of the case, for no blood appeared in the urine after operation nor was its amount increased. The patient was much relieved as a result of this incision into the kidney and urine escaped from the wound without any dimination in its quantity until Feb. 5th, 1895. During the earlier part of this time there was an admixture of pus, but later it was almost normal. The quantity of urine passed by urethra varied from $10 \mathrm{oz}$. to $25 \mathrm{oz}$. in the twenty-four hours. A drainage-tube had been kept in the loin wound as it was considered best to give the opening in the kidney a chance to heal before the soft parts. As the flow of urine did not diminish and the diagnosis was that a small calculus obstructed the ureter exploration of the ureter was decided on and carried ont on Feb. 5th through an incision in the right linea semilunaris. The ureter was traced from the renal pelvis down to the bladder. No stone could be felt and the only thing that appeared unusual was a limited thickening, not well defined, where the ureter crossed the pelvic brim; above this the ureter appeared to be somewhat dilated, below it was apparently normal. The pelvis of the kidney was normal and it was very interesting to find that the kidney itself had resumed its proper size and shape. Examination of the bladder after dilatation of the urethra with the finger yielded a negative result, as also did examination by the rectum. The wound was sutured in layers. Incontinence of urine followed and lasted for five days, but she suffered no further inconvenience from the examinations. As no calculus had been found in the urinary passages and obstruction continued it was decided to try what pressure from above would do and with this object the drainage-tube was removed from the loin wound which was allowed to close. No result was apparent until Feb. 19th, when the patient complained of severe pain on micturition and passed a pulpy mass of greyish colour, of the size of a hazel nut with $11 \mathrm{oz}$. of urine. In less than three hours' time $18 \mathrm{oz}$. were passed without pain. The wound in the loin rapidly closed, the quantity of urine passed daily was natural, there was no pus in it. and the patient was able to leave the hospital on Feb. 24th and has continued well since.

The history of old attacks of renal colic made it appear probable that the case was one of blocking of the ureter by a calculus and the formation of an acute pyonephrosis. At all events it appeared probable that the sudden onset of symptoms indicated an obstruction of the ureter from within, and when at the first operation the only stone found was in the abscess carity and not definitely in the pelvis of the kidney or entrance of the ureter, when the urine from the affected kidney all came through the lumbar wound and it was evident that the obstruction continued, exploration was clearly indicated. The result of this being negative as regards calculus made it probable that the block was caused by some softer substance, but the condition of the ureter as found at the second operation did not help very much in the clearing up of this point. The complete recovery from such a large pyonephrosis is also noteworthy, for the kidney was apparently normal when examined on Feb. 5th through the abdominal incision.

Mansfleld-street, W.

\section{ON PRIMARY ENTERECTOMY IN CASES OF INTESTINAL GANGRENE, WITH AN ILLUSTRATIVE CASE.}

BY CUTHBERT LOCKYER, M.B., B.S. LOND., F.R.C.S. ENet.,

P ATHOLOGEST TO THE GAMARITAN FRKK HESPITAL FOR WOMGN ; BURGICAL REGISTRAR TO CHARING-CROSS HOSPINAT AND DEMOLSTRATOR OF SURGERY IX THE MEDICAX SCHOOL.

Primary resection as a treatment for gangrenous bowel was for years the subject of controversy among surgeons. Before the use of the various cylinders and plates it was doubtless preferable in many cases to produce an artificial anus with a view to subsequent resection rather than immediate enterectomy, on the ground that owing to the very critical condition of patients suffering from acate obstraction the prolonged and tedious operation for suturing the gat after resection would not be well borne. By the aid of the various mechanical devices of recent invention the slow process of Lembert's stitching is rendered unnecessary and the time taken to complete the anastomosis is reduced to a minimum. It has thus come about that the entire operation of resection and bowel union has been effected in the short space of twelve minutes and the possibility of such a feat bas given popularity to the plan of removing gangrenous or suspicious bowel as soon as the latter has been cut down upon. On turning for a moment to the teaching of statistics overwhelming evidence is to be found in favour of primary resection of gangrenous bowel ; for instance, Lock wood, ${ }^{1}$ af ter analysing 37 cases of gangrenous hernia treated by artificial anus at St. Bar. tholomew's Hospital, finds that this method yields a mortality of 89.18 per cent. Again, Mikulicz ${ }^{2}$ showed that in 168 cases which were collected from the practice of seven operators and in which the two opera tions-resection and the formation of an artificial anuswere included the mortality after resection amounted to $47 \cdot 1$ per cent., whilst that after the formation of an artificial anus amounted to 76.6 per cent., and Mikulicz himself performed 21 resections with 14 recoveries, and of the 7 deaths only 2 were attributable to the method employed, whilst in 7 cases in which he made an artificial anus all ended fatally. Zeidler's ${ }^{3}$ figures throw light upon the treatment of gangrenous hernia; 289 cases of resection show a mortality of just over 49 per cent., whilst 287 cases of formation of an artificial anus show a mortality of over 74 per cent. - i.e., 25 per cent. greater. Glass ${ }^{4}$ in 1897 collected 48 cases of resection with 3 deaths or 6.25 per cent. McCosh ${ }^{5}$ tabnlates 115 cases of resection. of which 50 per cent. were fatal, and Razoumowski of St. Petersburg collected 26 cases of primary resection for strangulated hernia with 7 deaths only -12.26 per cent. It will be seen, therefore, from the above statistics that primary resection of sphacelating gut gives the patient the best chance of recovery in the majority of cases. I do not mean to imply by this that the older operation is to be entirely abandoned ; that cannot be, for in cases of diffuse peritonitis or in cases of profound collapse resection would be out of the question and the establishment of an artificial anus the only justifiable surgical procedure. Likewise in cases of marked meteorism and distension all that can be done is to make a temporary opening in the distended gut.

Having assigned to primary enterectomy its proper place in surgery the question which next presents itself is-What method shall be employed in the intestinal anastomosis? Having regard to methods in vogue a threefold choice is open to the operator: (1) simple suturing; (2) suturing with the aid of temporary splints; and (3) the use of metal buttons. The method of suture with a temporary splint is the oldest, for French surgeons employed the trachea of a calf for this purpose in the thirteenth centary. Next in point of antiquity is the simple suture which was first successfully performed by Ramdohr in 1780. The metal bobbin was first heard of in 1847, when Deman employed a combination of three rings and a spring in bowel union; this is the prototype of the Murphy button. I may say at once that each plan bas its supporters. There are surgeons who advocate the use of unaided suture to the exclusion of all mechanical assistance on the other hand, there are surgeons who invariably give the sutured bowel the support to be derived from a button on a bobbin. The latter class of operators differ only in their opinion as to the relative advantages of the metal battons as compared with the bobbins made of decalcified bone With regard to simple suturing several plans have been devised. First come the Lembert and Czerny-Lembert stitches. To the use of these for end-to-end anastomosis there are objections. Both Jacobson and Treves are agreed that from twenty-five to forty-five stitches are required, and these will take considerable time to adjust. Moreover, for approximation by suture one requires good healthy peritoneum to work upon, and this cannot always be obtained especially in cases where adhesions exist, for here peritoneum

1 Annals of Surgery, 1890.

2 Schmidt's Jahresbiīcher, Leipsic, May 13th, 1892. 3 Centralblatt für Chirurgie, Leipsic, Jan. 2lst, 1893

4 Transactions of the Medical society of New York, 1897, p. 383. 5 Medical and Surgical Reports of the Presbyterian Hospital, Nor York, 1896, vol. i., p. 160 . 
as such may have disappeared in newly formed tissue or after separation become too attenuated to support the sutures; therefore it is clear that there are cases where simple suture cannot be carried out. Many surgeons argue also that it is not always possible to effect a watertight union by the Lembert stitch. Maunsell's method of suturing bas promised much, especially in intussusception, but it is open to the serious objection that the stitches pass through all the coats of the bowel and leakage of intestinal contents may follow its use, as was shown to have occurred in three cases recorded by Bidwell from the practice of the West London Hospital ; and, furtber, the line of anion has been known to yield, giving rise to septic peritonitis. Mayo Robson says the peritoneum is more likely to be infected by this than by any other method of suture. A method of suture not generally practised, but which strongly appeals to me, is that devised by Leonard Rogers. ${ }^{7}$ He acts on Greig Smith's statement that a sero-fibrous is the firmest union, and accordingly strips a collar of serous membrane from one of the cut ends of the gut, thus baring its muscular elements; he then sews the serous coat of the other end to the muscular coat of the end prepared, draws the peritoneal collar over the first row of stitches and sews the edge of the collar to the serous coat of the other end of bowel. There are therefore two rows of stitches, one through serous and muscular (now buried) and one uniting serous to serous. The serous coat strips easily and the operation takes half an hour. This plan acted well in the case of dogs experimented upon by Rogers, but has not yet to my knowledge been tried on the human subject. The time taken up in suturing will, I think, militate against its becoming the favourite method of union, but it has very strong supporters in Harrison Cripps, Bruce Clarke, and Abbé, the latter surgeon having discarded his catgut rings in farour of plain suturing. In comparing the statistics of the suture with those of approximation by mechanical means I find that in Mayo Robson's ${ }^{8} 26$ cases the mortality for anaided suture was 55.3 per cent., whereas the mortality in oases where his bone bobbin was used was only 8.3 per cent. Weir was able to collect 35 cases of primary suture in which all the patients died. It is only fair to mention that Wdmunds and Ballance, ${ }^{9}$ as the result of operations on the thicker intestines of dogs, came to the conclusion that simple suturing is the best plan both for lateral and for endto-end anastomosis. For the former they advise Halstead's and for the latter Mannsell's method. The salient objection to simple unaided stitching is that it takes up so much more time than union by a button, and since it must be granted that it cannot be suitably adapted to meet all cases I will take in review the various mechanical appliances at the command of the surgeon. Some are digestible but others are not. Of the former I may mention Neuber's, Mayo Robson's, Allingham's, Ball's, and Bailey's decalcified bone bobbins, also Senn's plate and Paul's invagination tubes, Abbé's catgut bobbin and Beasley's catgut and rubber ring. Then come the non digestible supports, such as Murphy's button, with modifications by Jackson Clarke and also by Miller, Frank's coupler, Chaput's bobbin of malleable tin, A. J. Downe's (Philadelphia) rubber collapsable bags, and further suggestions have been offered by Cheatle, Hastigan, and Frank.

To make a comparison between the relative merits of the several appliances would occupy more space than is placed at my disposal. I will content myself by saying that were it not for the fact that Murphy's metal button has such a brilliant record of successes to show I would leave the metal bobbin out of consideration altogether. The great plea for the use of any appliance is that by so doing the operation is shortened in point of time and better union is likely to be got when the bowel is kept at rest by a temporary splint. Since Murphy's button has been so far the most popular instrument its merits and demerits are worthy of discussion. Its merits rest on results. Marphy ${ }^{10}$ records 27 cases in which the button was used with 9 deaths, and 5 only of these were from preventable causes. In Robson's hands the button had a mortality of 20 per cent. In 1896 Banks records its use in 7 cases with 2 deaths. Kummell ${ }^{11}$ collected 17 cases of resection

7 Brit. Med. Jour., 1896, vol, i., p. 903

8 Transactions of the Clinical Society of London, 1896, vol. xxix p. 142.

9 Edmunds: Transactions of the Royal Medical and Chirurgical Society, 1896, vol. lxxix., p. 255.

11 Archiv für Klinische Chirurgie, Berlin, 1896, Band ltii , p. 87. in 15 of which Murphy's button was used; 3 deaths occurred soon after operation, and of the remaining 12 all lived for some considerable time and 6 are recorded as having completely recovered. Carle ${ }^{12}$ has used the button fifty times with good results and he also records that during the last two years he and his assistant Fantino bave used the button twenty times for gastro-enterostomy with no death. In Graff's collection of 25 cases for 1893 to 1895 the button was in no case the cause of death. Individual saccesses are far too numerous to mention. Despite such a run of good fortune very serious objections present themselves in the use of the button. Amongst the many drawbacks may be mentioned (1) stenosis of the gut as a sequel ; (2) obstraction of the small Iumen; (3) failure to pass (4) gangrene extending from the seat of pressure or set up by the button in its passage down the canal ; (5) injury to the bowel during c'osure by the pressure of the fingers causing the sharply cut apertures for drainage to lacerate the mucous membrane ; (6) impossibility of disarticulating the button once it is closed; and (7) erosion of the spring by gastric juices. Chaput ${ }^{13}$ cites 3 cases of stenosis and Ball ${ }^{14}$ records a case, but this is not peculiar to Murphy's method; in my opinion it is far more frequent after simple guture. Chaput mentions 4 cases of obstruction and he does not agree with Meyer and Murphy, who say that purgation will overcome this difficulty. As to delay in passing there are many cases on record where the button has not passed at all. Murphy mentions 4 cases, Meyer 2, and Morton 1. In Allas's ${ }^{15}$ case the button was retained for 16 , months and in Wyeth's ${ }^{16}$ case for 127 days. In Quenin's case it was retained till death 16 months later. Kammerer attempted extirpation after the button had been retained for 12 weeks and the patient died from peritonitis. The ileo-cæcal valve is the point of hindrance to the passage of the button, for in the case of double resection recorded by Glass the button he inserted into the large intestine passed on the fifth day, whilst the one which united the ends of the small gut took 28 days in its passage. The long delay of the button in the bowel is a very serious drawback. Its presence, as will be seen in the case published below, gives rise to sharp attacks of colicky pains and localised tenderness; but, what is worse, it may give rise to a series of ulcers along the alimentary tract and some of these may perforate. Again, gangrene and perforation have cccurred 20 times to Chaput's knowledge. Quite recently this accident happened in a case at Charing-cross Hospital under the care of $\mathrm{Mr}$. Morgan, and most surgeons are acquainted with this serious objection. I believe the objection raised to the use of the button in operations on the stomach is entirely theoretical, for there is very little hydrochloric acid present in cases of gastroectasis, especially if the stricture is malignant, and it would be a very simple matter to gild the button if necessary. These manifold objections have resulted in modifications of the button being devised by Jackson Clarke, Miller, and others, and new methods of anastomosis are still being suggested by Cheatle, Frank, and Hastigan. In point of dispatch Murphy's plan of anastomosis is facile princeps and its introduction is a matter of extreme simplicity, and for these reasons it will always have a place in intestinal surgery. The main risks in its use lie in its slow passage endangering the entirety of the bowel and the liability to gangrene of the bowel around the button whilst it remains in situ. I predict, therefore, that the decalcified bone bobbins will ultimately prove to be of greatest zervice in aiding intestinal anastomosis.

A woman, aged seventy-seven years, was admitted into Charing-cross Hospital under the care of Mr. Bloxam on Aug. 16th, 1897. She was suffering from strangulated femoral hernia. Two months before admission to hospital she fell down a flight of twelve steps and afterwards noticed a swelling in the right groin. Four days before admission to hospital acute symptoms set in and became aggravated up to the time of admission. The patient was operated upon at once. When the sac was opened a quantity of thick, grumous, fotid fluid escaped and a knuckle of small intestine about 4 in. in length was exposed. The loop was intensely congested and at its convexity there was a gangrenous patch of the size of a florin. The vessels of the

12 Riforma Medica, Napoli, 1897, vol. xili., part 3, p. 541.

13 Bulletin de la Société de Chirurgie, Paris, July 24 th, 1895.

14 Brit. Med. Jour., vol. 1., 1897, pp. 1021, 1095, 1320.

Nashville Journal of Medicine and Surgery, 1896, pp. 79, 161 
corresponding portion of the mesentery were congested bat were not thrombosed. Having regard to the patient's great age the establishment of an artificial anus was suggested, but the anæsthetist (Mr. Bellamy Gardner) agreeing that the operation could proceed a portion of the gat $4 \frac{1}{2}$ in. in length was removed, the stricture having been eased by a vertical cut directly upwards through Poupart's ligament. A Murphy's button with a diameter of $\frac{15}{16}$ in. was inserted in the usual way and all bleeding points in the mesentery were secured. The parts were cleansed with a 1 in 2000 perchloride solution and the bowel together with the mesentery was returned into the abdominal cavity through the enlarged crural opening. The sac was ligatured and cut off, the deep parts were united with a fishing gut stitch, a drainage tube was inserted between the skin and the muscular planes and the superficial wound was sewn with interrupted fishing gut sutures. The pulse was 104, regular, and stronger after the operation than it had been before it. In the after treatment nothing was given by the mouth except sips of warm water for four days; small nutrient enemata were administered every two hours and all were retained. The patient passed a large stool from the lower bowel during the night after the operation. Two days after the operation flatulence became troublesome and great relief was obtained from turpentine enemata. The drainagetube was retained for two days. The superficial wound suppurated for a while owing to contamination by the fluid in the hernial sac at the time of the operation. Hypostatic congestion set in at the bases of the lungs ten days after the operation. The patient suffered from colicky pains and some localised tenderness in the right iliac fossa which was worse at some times than others and these were complained of until the button was passed on the thirtieth day after operation. She left the hospital five weeks after the operation. I visited the patient at her home on Jan. 19th, 1898, and found that the wound was sound, that there was no sign of hernia on coughing, that the bowels were acting quite regularly and without pain, and that beyond the fact that she was seventy-eight years of age she had nothing to complain of.

$I$ believe that the pain and tenderness in the right iliac fossa noted in the above case were caused by the button's passage being obstructed by the ileo-cæcal valve. That the button might be in the rectum was put out of court by examination for it in that situation. With regard to the division of Poupart's ligament, as Ball has pointed out, this does not weaken the abdominal wall any more than an incision in any other part of the abdomen. In the above case the soundness of the wound at the present time bears out this statement. Resection through the original wound presents less risk of infection than the plan practised by some surgeons of opening the abdomen and drawing the gangrenous bowel from the crural canal across the peritoneal cavity and resecting through a second wound. The great age of the patient is the most remarkable feature in the case. I am indebted to $\mathrm{Mr}$. Bloxam for permission to publish the case and also to Mr. Morgan for permiasion to mention a recent case of his by way of illustrating a point in this paper.

Charing-cross Hospital.

Llanelly Hospital.-Owing to the resignations of the nursing staff at the Llanelly Hospital the committee of that institution has decided to temporarily close the hospital except in cases of serious accidents.

The Neurological Soctety of London.--This society held its first meeting out of London on April 23rd, when, at the invitation of Dr. Alezander Hill, vice-Chancellor of the University, a meeting was held in the Physiological Laboratory at Cambridge. The following communications were made :-Dr. Alexander Hill : Some Specimens of Granules (demonstration).-Professor MacAlister : The Racecharacters of Australian Brains (demonstration).-Dr. J. N. Langley : Some Points relating to the Sympathetic System (demonstration).-Dr. Gaskell (for Miss Alcock): The Distribution of the Facial Nerve in Ammocotes.-Dr. F. E. Batten : (1) Nerve Terminations in Muscle Spindles (demonstration); and (2) (for Dr. Sihler of Ohio), Motor Nerve Termination within the Muscle Spindle (demonstration).Dr. Mott: Degeneration of the Neuron (demonstration). At the conclusion of the meeting members and visitors were entertained at dinner by the Vice-Chancellor in Downing Hall.

\section{Clinital âtotes:}

\author{
MEDICAL, SURGICAL, OBSTETRICAL, AND \\ THERAPEUTICAL.
}

\section{NOTES ON FOUR CASES OF PUERPERAL ECLAMI YSIA.}

BY G. FowLer, L.R.C.P. EDIN.

CASE 1.-The patient was a married woman, aged eighteen years, eight months pregnant with her first child. There was no neurotic family history. The patient enjoyed perfect health till the day before I was sent for. She then com. plained of giddiness and flashes before her eyes and voided a very small quantity of urine which coagnlated into a semisolid maddy-looking mass. When $I$ arrived at the house in the morning she had passed a restless night and complained very much of "slight twitches" (spasmodic contractions) of her hands and feet. I gave her full doses of chloral and applied mustard sinapisms to her calves. Two hours after I was hastily summoned as she had had a general convulsion and was quite unconscious. I found her in a violent genera? epileptiform seizure, having bitten her tongue rather severely. I tried to prevent ber from further damaging her tongue by means of a gag and at once administered chloroform and kept her under its influence for nearly half an hour As long as she was under the anæsthetic no convulsion existed, but as soon as its effects had passed away the fits came on again at regular intervals. As a last resource, considering the gravity of the case, with the consent of those most interested in her, $I$ induced premature labour, dilating the os by means of Hegar's dilators and Barnes's bags, anc when the os had fully dilated ruptured the membranes and delivered her with Simpson's long forceps. The whole operation lasted some time but was to my entire satisfaction. The child was stillborn. After delivery the mother had one severe convalsive seizure and from this time all proceeded well, the patient gradually recovering consciousness but having no recollection of what had occurred for some hours previous to or daring labour. Since then I have delivered this patient of her second child, a healthy male, which presented in an occipito-posterior position.

CASE 2.-The patient was a married woman, aged twenty. one years, seven months pregnant with her first child. I was hurriedly summoned to see her as she had had a number of fits and was quite unconscious. When I arrived I found that both the upper and the lower extremities were very much swollen and odematons. Urine had not been voided for twenty-four hours. Digital examination revealed an almost fully dilated os, a roomy pelvis, a cranial presentation, and the membranes intact. Fearing the onset of further convalsions I at once ruptured the membranes and awaited the result. This increased the uterine contractions, but unhappily while the head was rapidly descending a severe convalsive attack came on resembling an epileptic fit and this seemed to stop the further progress of the labour. This convulsion was soon followed by another, the fits occurring at regular intervals. As the bead appeared to me to be acting as an irritant by its pressure, and being also well within reach, $I$ resolved upon instrumental delivery and delivered the patient without any difficulty of a living male child. The placenta followed rapidly. The patient had no more fits, passed urine eight hours after the birth of the child, and progressed favourably, the urine remaining albuminous for about three days. Both child and mother are now doing well.

CASE 3. - This patient resembled Case 1 in every respect. I treated her in the same manner and was successfal in delivering her of a living child. Both mother and child progressed favourably.

CASE 4.-The patient, a rather anæmic young woman with a good previous history, was taken in a fit four days after the birth of her first child, which was born without the aid of a medical man. The temperature was normal and the lochia were healthy. The urine was albuminons. There was no rupture of the perineum. The fits occurred at regular intervals and the patient remained in a semi-comatose state between them. I gave her full doses of chloral by the 